\title{
Validation of eDNA as a viable method of detection for dangerous cubozoan jellyfish
}

\author{
Brett Bolte $^{1}$ (D) | Julie Goldsbury ${ }^{1}$ | Roger Huerlimann ${ }^{1}$ | Dean Jerry Re $^{1,2,3}$ | \\ Michael Kingsford ${ }^{1,4}$ (D)
}

${ }^{1}$ Marine Biology and Aquaculture, College of Science and Engineering, James Cook University, Townsville, QLD, Australia

${ }^{2}$ Centre for Sustainable Tropical Fisheries, James Cook University, Townsville, QLD, Australia

${ }^{3}$ Tropical Futures Institute, James Cook University, Singapore, Singapore

${ }^{4}$ ARC Centre of Excellence for Coral Reef Studies, Townsville, QLD, Australia

Correspondence

Brett Bolte, Marine Biology and Aquaculture, College of Science and Engineering, James Cook University, Townsville, QLD 4811, Australia.

Email: brett.bolte@my.jcu.edu.au

\begin{abstract}
Stings from certain species of cubozoan jellyfish are dangerous to humans and their seasonal presence in tropical marine waters poses a significant risk to coastal communities. The detection of cubozoans is difficult due to high spatial and temporal variation in their occurrence and abundance. Environmental DNA (eDNA) has the potential to detect rare species and therefore offers potential to detect cubozoans, not only pelagic medusae, but presence of cryptic polyp life stages. The objective of this study was to validate the use of eDNA as a viable detection method for four cubozoan species (Chironex fleckeri, Copula sivickisi, Carybdea xaymacana, and Carukia barnesi). Species-specific primers were developed for each of these four cubozoans and an eDNA approach validated utilizing both laboratory and field trials. Laboratory DNA degradation experiments demonstrated that $C$. sivickisi DNA degraded quickly but could still be detected in sea water for up to 9 days post-jellyfish removal. Positive detection was found for C. fleckeri, C. xaymacana, and C. sivickisi medusae in the waters surrounding Magnetic Island, Queensland, in the Austral spring/summer (September-January). Based on visual surveys, there was a poor relationship between concentration of eDNA and abundance of jellyfish. Positive eDNA amplification was also found from water sampled near the substratum when $C$. sivickisi medusae were out of season and absent. This suggests the eDNA analysis was likely detecting $C$. sivickisi polyps located within the substratum. Consequently, eDNA is an effective tool to detect both the medusae and likely polyps of cubozoans. This approach provides the means to reduce the risk of envenomation to swimmers and enhance our knowledge of cubozoan ecology.

KEYWORDS

cubozoan, environmental DNA, Irukandji, jellyfish, PCR
\end{abstract}




\section{1 | INTRODUCTION}

The Cubozoa (box jellyfishes) are a class of jellyfish with relatively low species diversity ( 50 species; Bentlage et al. 2010; Kingsford \& Mooney, 2014). Many cubozoans are regarded as dangerous and even life-threatening venomous animals that pose challenges to managers of coastal resources in tropical and subtropical regions (Kingsford et al., 2018). One species, Chironex fleckeri, is considered one of the world's most venomous marine species and has been responsible in Australia for at least 70 deaths in the past 50 years, with mortalities now being increasingly recognized and reported from other Indo-Pacific countries (Kingsford et al., 2012; Seymour, 2002). Furthermore, envenomation from another 10 cubozoan species can result in the debilitating condition "Irukandji syndrome" (Ponce et al., 2015). Envenomations and Irukandji syndrome can lead to death, or serious injury, with symptoms that include lower back pain, muscle cramps, vomiting/sweating, vasoconstriction, prostration, possible hypertension, feeling of impending doom, and acute heart failure or death (Tibballs et al., 2012). Though these jellyfishes pose major health risks to humans, their spatial rareness and elusiveness makes detection in marine waters difficult and as a result their ecology and distribution is presently poorly understood (Kingsford \& Mooney, 2014; Tibballs et al., 2012).

Jellyfish have polymorphic lifecycles, where the pelagic adult medusa are the most conspicuous form. The small benthic polyp stages (asexual stages) are usually cryptic, with $C$. fleckeri the only cubozoan species where polyps have been detected in situ (Hartwick, 1991). This is because benthic cubozoan polyps are minute $(<2 \mathrm{~mm})$ and even the adult medusoid (sexual phases) of some taxa can be very small. This alone has contributed to the many challenges of studying cubozoans (Kingsford \& Mooney, 2014).

The biogeographic range of a species generally corresponds to a "metapopulation" made up of relatively autonomous "stocks" with little connectivity among them. Moreover, within stocks small geographic areas such as bays may be considered "local populations" that can have a high level of connectivity (Kingsford \& Mooney, 2014). Recent research has suggested that even small local populations of some cubozoans may have little exchange with other populations (Schlaefer et al., 2020); but critical to understanding levels of connectivity is a knowledge of the movements of medusa and the sources of polyps. The accurate detection of cubozoans is critical for minimizing the risk of envenomation to humans and to better understand their ecology (Kingsford et al., 2018). Another justification for understanding population structure and the dispersal potential of jellyfish is related to climate change. It has been predicted that jellyfish blooms will intensify in occurrence and the geographic range of deadly jellyfish will expand (van Walraven et al., 2016) specifically with Irukandji, southward down the Queensland coast. Given the potential changes in level of risk and the related threat to tourism, it is important to develop technologies that improve the detection of cubozoans as they expand their ranges.

Environmental DNA (eDNA) has the potential to greatly enhance research on the ecology of cubozoans and to assist managers of coastal resources to minimize the risks of envenomation (Kingsford et al., 2018). Environmental DNA technology is the detection of DNA shed in the environment by an organism as a part of normal metabolism, excretion, death, and reproduction. This technique has been used to detect rare (Jerde et al., 2011; Keskin et al., 2016; Simpfendorfer et al., 2016), invasive (Robson et al., 2016), and sporadically distributed species, including scyphozoan jellyfish. For example, Minamoto et al., (2017) used an eDNA approach to detect the presence of medusae of the Japanese sea nettle (Chrysaora pacifica) in Mazizuru Bay, Kyoto, while Gaynor et al., (2017) looked at the applicability of eDNA to detect early life stages of Chrysaora quinquecirrha in Barnegat Bay, New Jersey. However, to date, there has been no published works on the use of an eDNA approach to detect occurrence of venomous cubozoans and the focus has only been on ephyrae and medusa, not the benthic polyps.

The objective of this study was to develop and validate species-specific PCR primers that could be used to detect four cubozoan species that occur in marine waters along the east coast of tropical Australia, namely C. fleckeri, Copula. sivickisi, Carybdea xaymacana and Carukia barnesi. Of the species selected, the chirodropid C. fleckeri is considered highly venomous and deadly to humans, and victims of envenomation by the carybdeids $C$. xaymacana and C. barnesi often exhibit symptoms of Irukandji syndrome; C. sivickisi is harmless to humans. Our specific aims were as follows: (1) develop species-specific primers to detect presence of each of these cubozoans; (2) experimentally determine the degradation rate of cubozoan eDNA; (3) determine if eDNA could detect cubozoan medusae in the field and ascertain if the amount of eDNA correlated with abundance as estimated from visual surveys; (4) determine if presence of cryptic cubozoan polyps can be detected with eDNA at times when medusa are absent using $C$. sivickisi as the model organism.

\section{2 | METHODS}

\section{1 | Primer design}

Representative specimens of target cubozoans found in sympatry around the experimental field site of Magnetic Island, Queensland, were collected for sequencing. Sample locations and the cubozoan species collected were as follows: $C$. fleckeri $(n=1)$, Mapoon, Queensland; C. sivickisi $(n=9)$ Magnetic Island, Queensland; C. xaymacana, $(n=2)$, Magnetic Island, Queensland, C. barnesi $(n=1)$, Double Island, Queensland. Jellyfish were preserved in $80 \%$ ethanol and genomic DNA (gDNA) extracted using a Qiagen DNeasy Blood and Tissue Kit (Venlo, The Netherlands). A 584-bp fragment of the mitochondrial 16S rRNA gene for all the cubozoan species sampled were amplified via PCR using the published primers 16SL (Bayha et al. 2010) and Aa_H16S_15141H (Ender and Schierwater (2003) and the following PCR thermocycling conditions: $94^{\circ} \mathrm{C}$ for $3 \mathrm{~min}, 38$ cycles of $94^{\circ} \mathrm{C}$ for $45 \mathrm{~s}, 48^{\circ} \mathrm{C}$ for $1 \mathrm{~min}, 72^{\circ} \mathrm{C}$ for $1.5 \mathrm{~min}$, followed by a final extension step of $72^{\circ} \mathrm{C}$ for $10 \mathrm{~min}$. The resultant PCR product was size verified on a $1.5 \%$ agarose electrophoresis gel and remaining product purified using a Zymo One Step PCR inhibitor removal 
kit, following manufacturer's instructions. Products were then sent for Sanger sequencing at the Australian Genome Research Facility, Brisbane, Australia. Sequences were edited and aligned in Geneious Prime ${ }^{\circledR}$ 2019.0.4. A blastn search against the NCBI nucleotide database was performed to confirm the taxonomy of the jellyfish and to identify likely polymorphic sites among species suitable for the design of species-specific eDNA primers (Appendix S1).

$16 \mathrm{~S}$ rRNA sequences lodged within the NCBI database for the target species were downloaded and aligned along with the sequences generated from jellyfish sequenced in the present study (total sequences for primer design; $C$. fleckeri $n=4, C$. sivickisi $n=11$, C. xaymacana $n=5, C$. barnesi $n=3$ ) and species-specific primers designed that amplified a region within the mtDNA 16S rRNA gene using Geneious Prime ${ }^{\circledR}$ 2019.0.4. To check primer species-specificity, primers for each species were first in silico checked for co-amplification against aligned multiple sequences of all other target jellyfish species, as well as directly through PCR. Jellyfish sequences within NCBI came from different populations from those we sequenced and within a species no intraspecies polymorphism was observed at priming sites. Amplicons were visualized on a $1.5 \%$ agarose electrophoresis gel at $80 \mathrm{~V}$ for $40 \mathrm{~min}$, with no cross-amplification observed among species primer sets (Appendix S2).

\subsection{Quantitative PCR}

For C. sivickisi, the RT-PCR analysis was based on a TaqMan hydrolysis probe (Cop_siv_16S_P-5'- CACTCCGCTTATCAA -3') assay (Table 1) developed using Geneious Prime ${ }^{\circledR}$ 2019.0.4. Each qPCR was run on a QuantStudio 5 Real-Time PCR machine (Thermo Fisher Scientific) and consisted of $5.0 \mu \mathrm{l} 1 \times$ TaqPath, $0.9 \mu \mathrm{M}$ Copula_16S_F (Forward), $0.9 \mu \mathrm{M}$ Copula_16S_R (Reverse), $0.25 \mu \mathrm{M}$ Copula_16S_P probe, $2.5 \mu \mathrm{l}$ sample, and $0.7 \mu \mathrm{l}$ of MilliQ for a final reaction volume of $10 \mu \mathrm{l}$. Results were obtained using optimized thermocycling; hold for $5 \mathrm{~min}$ at $95^{\circ} \mathrm{C}$, then 40 cycles of $15 \mathrm{~s}$ at $95^{\circ} \mathrm{C}, 30 \mathrm{~s}$ at $60^{\circ} \mathrm{C}$.

For all other species' primers (C. fleckeri, C. xaymacana, and C. barnesi), eDNA detection was via an intercalating dye assay (SYBR Green Power Up), with each reaction consisting of $1.4 \mu \mathrm{l}$ MilliQ, 10 $\mu \mathrm{l} 2 \times$ PowerUp SYBR Green, $0.9 \mu \mathrm{M}$ Forward primer, $0.9 \mu \mathrm{M}$ Reverse primer, $5 \mu \mathrm{l}$ sample for a final reaction volume of $20 \mu \mathrm{l}$. This reaction volume was chosen due to the lower specificity when compared to the TaqMan hydrolysis probe and ran starting with 2 min at $50^{\circ} \mathrm{C}$, 2 min at $95^{\circ} \mathrm{C}$, then 50 cycles of $95^{\circ} \mathrm{C}$ for $15 \mathrm{~s}$, followed by $65^{\circ} \mathrm{C}$ for $1 \mathrm{~min}$. At the end of the qPCR run, a melt curve analysis was conducted to confirm there was no contamination $\left(15 \mathrm{~s}\right.$ at $95^{\circ} \mathrm{C}, 1 \mathrm{~min}$ at $60^{\circ} \mathrm{C}, 15 \mathrm{~s}$ at $95^{\circ} \mathrm{C}$ ) (Appendix S3). Each sample was run in triplicate, with each plate consisting of a qPCR no-template control (replicates consisting of all qPCR reagents and water, but no DNA template to confirm absence of contamination within reagents). Quantitative PCR and PCR plates were prepared in a laminar flow hood within a sterilized room. For quantification of DNA in each of the samples, a standard curve was created. This standard curve used a 10-time dilution series, [(C. fleckeri: $157 \mathrm{ng} / \mu \mathrm{l}$ to $1.57 \times 10^{-9} \mathrm{ng} / \mu \mathrm{l}, 98.4 \%$ efficiency, $R^{2}=0.999$ ), (C. sivickisi: $5.9 \mathrm{ng} / \mu \mathrm{l}$ to $5.9 \times 10^{-6} \mathrm{ng} / \mu \mathrm{l}, 95 \%$ efficiency, $R^{2}=0.994$ ), and (C. xaymacana: $10 \mathrm{ng} / \mu \mathrm{l}$ to $1.0 \times 10^{-6} \mathrm{ng} /$ $\mu \mathrm{l}$, 93.7\% efficiency, $\left.R^{2}=0.999\right)$. Water samples that produced a PCR product were sent for Sanger sequencing (AGRF, Brisbane, Australia) to confirm the species-specificity of the resulting PCR product. For all species, amplification of a single technical replicate deemed the sample replicate as a positive detection.

\subsection{Water sampling and eDNA preservation}

In the field, seawater was collected in sterile $2 \mathrm{~L}$ plastic bottles based on volumes used in previous studies in our laboratory and other studies on the detection of rare and invasive species (Robson et al., 2016; Simpfendorfer et al., 2016; Uthicke et al., 2018). For all field experiments, prior to sampling, all equipment was soaked in $10 \%$ bleach for $2 \mathrm{hr}$ and then rinsed with reagent-grade water $(\times 3)$ to eliminate the risk of contaminants. Equipment controls, where $500 \mathrm{ml}$ of sterilized water was passed through the water pump and filters before placed into Longmire's solution, were taken before sampling at each of the sites to detect for possible cross contamination of equipment.

Environmental DNA was extracted from sea water samples using a workflow process (Preserve, Precipitate, Lyse, Precipitate, Purify

TAB LE 1 Species-specific mtDNA 16S rRNA primer sequences for four cubozoan species, showing the length (bp) of final PCR fragment, as well as the assay type (SYBR or TaqMan)

\begin{tabular}{llll} 
Species & Primer & Sequence (5'-3') & Length PCR Fragment (bp) \\
\hline C. sivickisi & Cop_siv_16S_P & CACTCCGCTTATCAA & 199 \\
& Cop_siv_16S_F & CTGTCGAGCTTAATTGGTATC & \\
Cop_siv_16S_R & AAGGCGGGGTATTAACAC & \\
C. fleckeri & Chi_flec_16S_F & GAAGCCTTAGGGAGACACGAG & 172 \\
& Chi_flec_16S_R & GAACGGAGGGTCACTATAACTTAGC & \\
C. xaymacana & Car_xay_16S_F & TCTATCTGTTGCAACAAAGGTCC & 127 \\
& Car_xay_16S_R & GACCCACAGATTTCGTGACTG & \\
C. barnesi & Car_bar_16S_F & TGAGGCCTGCTCACTGATTC & 280 \\
& Car_bar_16S_R & CAACCAAACTAGCCCCTTTCTTC & \\
\hline
\end{tabular}


(PPLPP)), (Villacorta-Rath et al., 2020). (Appendix S4). Extraction controls and MilliQ water with all reagents used the same PPLPP protocol to detect contamination in any of the reagents. Once precipitated through the PPLPP process, DNA was purified using the Zymo One Step PCR Inhibitor Removal Kit (Irvine, California, USA).

\section{4 | Experiment 1: DNA Degradation}

A DNA degradation experiment was conducted using $C$. sivickisi to determine how quickly eDNA may degrade once the jellyfish is removed in a temperature-controlled environment $\left(20^{\circ} \mathrm{C}\right)$. Decay to $<1 \%$ of the original eDNA concentration has been found in some studies to take anywhere from 48 hr to 10 days (Pilliod et al., 2014; Thomsen et al., 2012); however, no estimates were available for cubozoans. In this trial, C. sivickisi medusae were collected at night off the coast of Magnetic Island, North Queensland (24/09/2019). Once collected, a single adult jellyfish (interpedalia distance $2-3 \mathrm{~cm}$; $n=16)$ was placed in a $10-L$ bucket $(n=16)$ filled with $7 \mathrm{~L}$ of artificial saltwater mixed to $35 \mathrm{ppt}$ to mimic that of the ocean. After $12 \mathrm{hr}$ the medusa was removed. Equipment controls involving filtration of $500 \mathrm{ml}$ of MilliQ water were taken prior to filtering sample water to detect any contamination that may have been in the filtering apparatus. Prior to sampling, all buckets were stirred to homogenize the water to confirm results do not represent DNA settling. Each bucket $(n=4)$ was sampled once so that all samples were independent with the full $7 \mathrm{~L}$ of water being filtered through $5 \mu \mathrm{m}$ nylon filters. The filtering of water ( $n=4$ buckets per time) was undertaken on days 0,3 , 6 , and 9 after the removal of jellyfish to determine the concentration of eDNA remaining in the water column. Filter papers were placed in sterilized $2 \mathrm{ml}$ tubes containing $1 \mathrm{ml}$ of Longmire solution (Renshaw et al., 2015; Williams et al., 2016) and stored at $4^{\circ} \mathrm{C}$ for future extraction and analysis.

\subsection{Experiment 2: Field experiment}

Abundance estimates: Over the course of 5 nights, estimates of abundance of medusae were obtained at known jellyfish "hotspots" (Schlaefer et al., 2020) between September and November for C. sivickisi and one night for C. xaymacana. Sites were separated by tens to hundreds of meters in shallow waters near Magnetic Island, North Queensland $\left(19.1359^{\circ} \mathrm{S}, 146.842^{\circ} \mathrm{E}\right)$. The medusae of C. sivickisi and C. xaymacana are photopositive and were attracted to lights using "JellyCams" (Kingsford et al., 2018); in this way, it was possible to estimate the presence and abundance of jellyfishes. Each "JellyCam" had an LED torch (2000 lumens) attached to weighted crates. The devices were lowered at each of the sites in 2-5 m of water and left for $30 \mathrm{~min}$ to attract cubomedusae for sampling. A snorkeler obtained an estimate of jellyfish abundance to a depth of $3 \mathrm{~m}$ and within a $2 \mathrm{~m}$ radius of the light over a course of $2 \mathrm{~min}$. Samples were taken at some sites without lights to determine if jellyfish DNA could be detected without attracting medusae toward a light. These were conducted in Nelly Bay with water being sampled within $0.5 \mathrm{~m}$ of the surface.

Water sampling: For C. fleckeri, water samples were taken during daylight hours in the Australian summer (January) in Horseshoe Bay, Magnetic Island, Queensland, from four sites separated by several hundreds of meters (creek, boat ramp, inside the stinger net, and northeast side of the bay). Horseshoe Bay was chosen due to historical data from Surf Life Saving Queensland (SLSQ) indicating that medusae were commonly present in the bay during the summer months (Dec-Feb). For C. sivickisi, C. xaymacana, and C. barnesi, Nelly, Geoffrey, Arthur and Florence Bays, Magnetic Island, were chosen, as medusae have previously been collected at these sites in the Austral spring/summer (September-January; (Schlaefer et al., 2020). Water samples were taken using sterilized $2 \mathrm{~L}$ containers collecting water within $0.5 \mathrm{~m}$ of the surface and within a $2 \mathrm{~m}$ radius of the JellyCams, JCAM, light. Controls $(500 \mathrm{ml}$ of MilliQ water) were filtered to detect potential contamination that was unrelated to the field samples taken at each site. Samples were stored on ice and taken back to the laboratory where they were pumped through either a $20 \mu \mathrm{m}$ (C. fleckeri samples due to high turbidity of sample), or $5 \mu \mathrm{m}$ (C. sivickisi, C. xaymacana, and C. barnesi) nylon filter (Merck Millipor, $47 \mathrm{~mm}$ diameter) within $12 \mathrm{hr}$ of collection (Appendix S5). Once filtered, filters were removed using sterilized forceps and placed into Longmire's preservative solution (Renshaw et al., 2015). All environmental samples were stored at $4^{\circ} \mathrm{C}$.

\subsection{Experiment 3: Detection of life stages}

The presence of $C$. sivickisi medusa in waters surrounding Magnetic Island is restricted to the spring-summer period (Schlaefer et al., 2020). This species, therefore, provided a good model to determine if eDNA could detect the presence of cubozoan polyps when medusae were absent. Water for eDNA analysis was collected from nearshore waters surrounding Magnetic Island, Queensland, at three sites separated by 300-400 m during the Austral winter (June 2019). Depth stratified water samples were collected into $1 \mathrm{~L}$ General Oceanics Niskin near the surface and just above the substratum; the total water column was 3-6 m deep. Sampling was targeted over coral reef largely covered by the macroalga Sargassum and dead coral matrix, as adult medusae are abundant over this habitat in the Austral spring and generally stay close to this preferred habitat (Kingsford et al., 2018; Schlaefer et al., 2020). Accordingly, this habitat is where embryo bundles would likely be released following copulation (GarcíaRodríguez et al., 2018). Water samples (2 L) were taken from "jellyfish hot spots" at Geoffrey Bay (Site 1, 19.15.332 ${ }^{\circ} \mathrm{S} \& 146.86479^{\circ} \mathrm{E}$; Site $2-19.15 .486^{\circ} \mathrm{S}, 146.86 .183^{\circ} \mathrm{E}$ ) and Nelly Bay (Site 3, $-19.17 .102^{\circ} \mathrm{S}$, $\left.146.84 .831^{\circ} \mathrm{E}\right)$, Magnetic Island. Samples collected during the winter were also taken after dark (1830-1930 hr as they were during the medusa season (Sept-Nov). Water was taken in sterile $2 \mathrm{~L}$ containers and placed on ice which were then filtered within $12 \mathrm{hr}$ of collection with field controls being taken at each site $(500 \mathrm{ml}$ of sterile MilliQ water). Filter holders were changed for each replicate to minimize the 
chances of contamination among sites and replicates. Individual filter holders were loaded with $5 \mu \mathrm{m}$ nylon filters. After filtration of each sample and equipment blanks, the nylon filters were placed in $1 \mathrm{ml}$ of Longmire solution and stored at $4^{\circ} \mathrm{C}$ for DNA extraction.

It was possible that stratification of the water column would influence level of detection of eDNA. Accordingly, conductivity (PSU), temperature and depth (CTD), measurements were taken at each site during the jellyfish season. These data were used to identify the presence/absence of thermoclines and haloclines in the water column, which could potentially inhibit the vertical dispersal of eDNA through the water column (Walther et al., 2013).

\subsection{Statistical analysis}

A one-way ANOVA test was used to test for differences in quantity of eDNA among days in the eDNA degradation experiment. Factors: (Day $a=4)$, and independent bucket replicates $(n=4)$. To meet the assumptions of ANOVA, the data were $\log (x+1)$ transformed. The test was conducted using the package Systat 13.

\section{3 | RESULTS}

\section{1 | Primers}

Species-specific primers were successfully developed for each target cubozoan. Each primer set was tested using exclusion PCR against all other cubozoan species found in the waters surrounding Townsville, North Queensland, and only amplified PCR product from the target species. No cross-amplification was observed.

\section{2 | Degradation experiment}

DNA $(0.08 \pm 0.043 \mathrm{ng}$ of eDNA/ $\mu \mathrm{l})$ was detected in buckets soon after the removal of jellyfish (Day 0 ) and observed to rapidly decay by Day 3 to about $23 \%$ of initial levels $(0.0185 \pm 0.0139 \mathrm{ng} / \mu \mathrm{l})$ where they plateaued (Figure 1). By Day 9 , eDNA levels were $<1 \%$ of initial concentrations and in some buckets was undetectable. An ANOVA detected significant differences among days $(d f=3,12, F=11.65$, $p<.01, \log (x+1)$ transformed data).

\subsection{Detection in the field}

In general, where the four species of jellyfish were known to occur, their eDNA was detected. Copula sivickisi was detected in $100 \%$ of replicates at sites $1 \mathrm{a}, 3 \mathrm{a}$, and $4 \mathrm{a}$. At some sites, no lights were used to attract jellyfish, but eDNA from these sites was still detected (sites 12a, 13a). eDNA was not detected in samples from two sites (10a, 11a), which had jellyfish present (Table 2). There was no correlation between abundance of $C$. sivickisi medusa in the field and quantity of eDNA (Figure 2; $r=-0.04, d f=23 ; p>.05$ ).

Carybdea xaymacana and $C$. fleckeri were relatively rare at the time of sampling and $C$. fleckeri was not detected visually, although they were known to be in the area due to observations and collection in tows from Surf Lifesaving Queensland. Carybdea xaymacana was detected by both JCAMS, and in two snorkeling surveys; however, only at two sites and with low species abundance. At the sites where visual observations detected the species, the species was also detected using eDNA (Figure 3).

To cross reference the eDNA approach for each species, negative sites were used for C. xaymacana and C. barnesi. Negative detections at some sites suggested that false positives were unlikely. The primers of $C$. xaymacana and $C$. barnesi were used in multiple water samples in Geoffrey Bay $(n=5)$ these species had not been found at these sites, and all samples showed negative detection (Table 2). Similarly, C. fleckeri was only found at two sites with negative detections at the other two sites in Horseshoe Bay. Carukia barnesi was never visually detected during sampling and this concurred with zero detection with eDNA (Table 2).

A reverse thermocline was detected at $2 \mathrm{~m}$ with no significant halocline being detected.
FIGURE 1 Quantity of DNA (ng/ $\mu$ l) after filtering $7 \mathrm{~L}, n=4$, of water from four independent tanks over a course of 9 days. Filtering was undertaken 0 , $3,6,9$ days post removal of jellyfish to determine the rate of DNA degradation. Standard errors are shown as bars for level of eDNA at each day
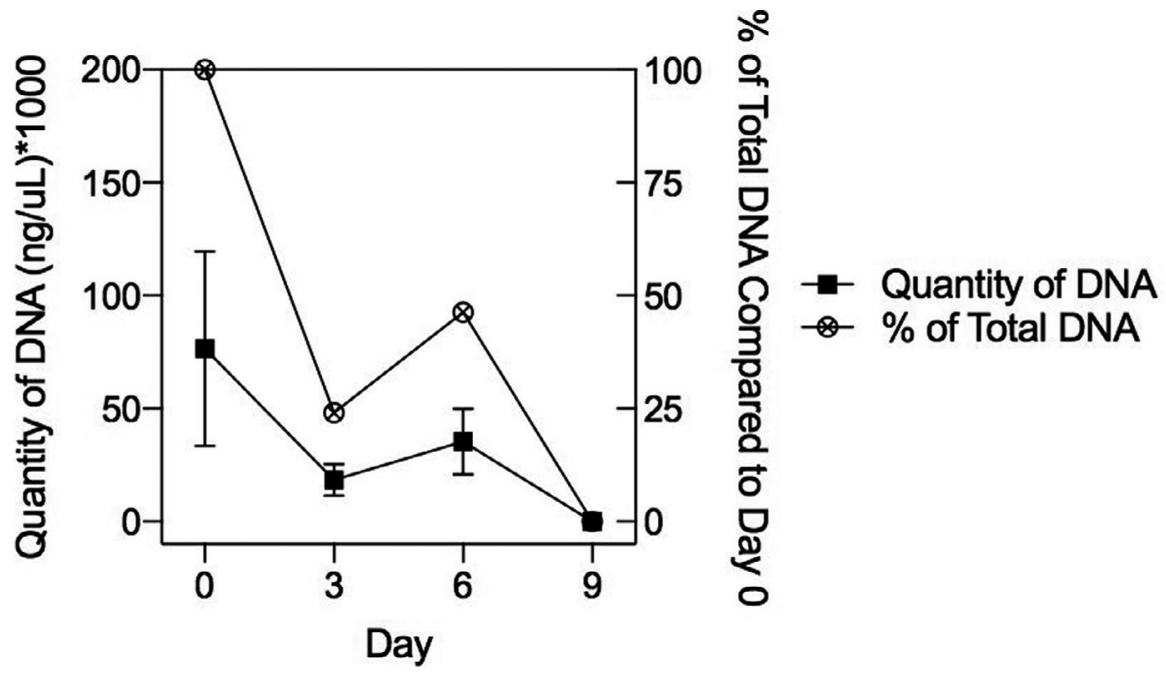


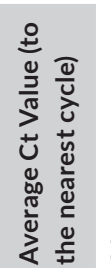

유 $\stackrel{\cdots}{N}$ సे

ભ ભ

ले ले

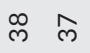

$\infty$

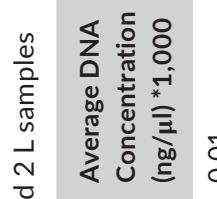

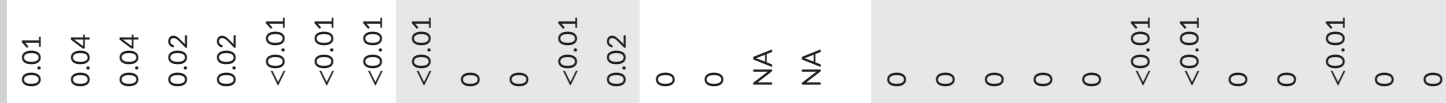
离
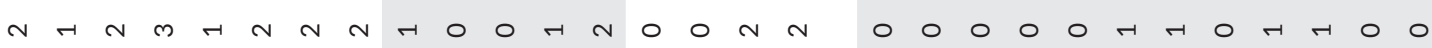

每 雷

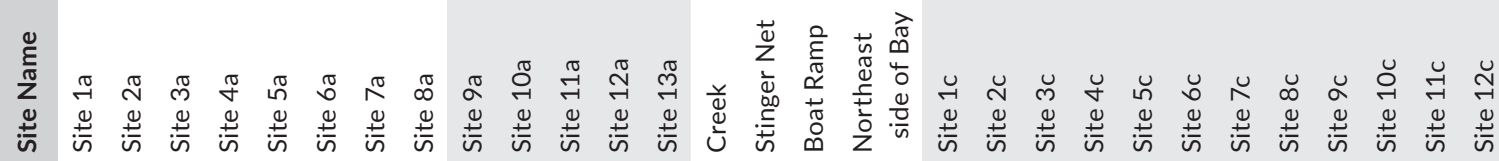

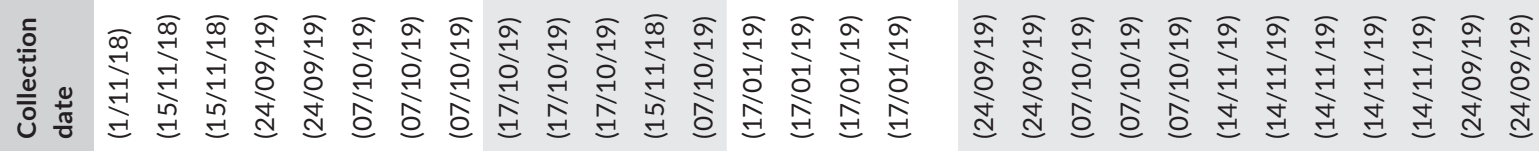
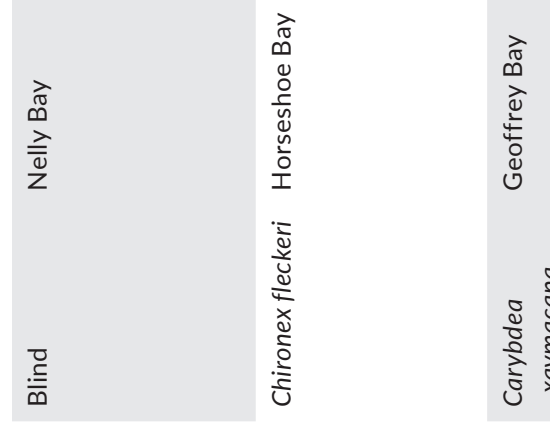


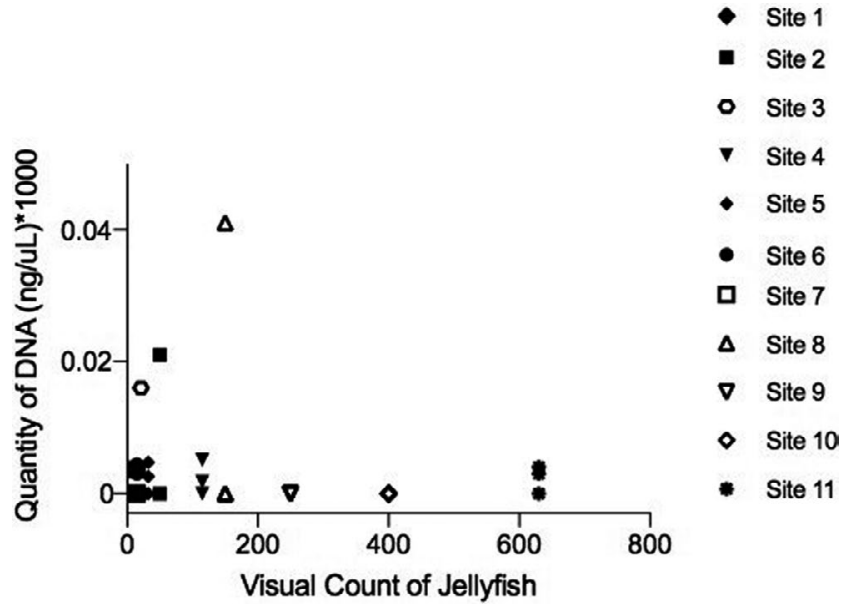

FIGURE 2 Correlation between visual abundance counts of Copula sivickisi and average quantity of DNA (ng/ $\mu$ l) at the respective site within Geoffrey and Nelly Bay, Magnetic Island. Sites which provided amplification (11) are represented by a different symbol

When the adult medusae of $C$. sivickisi were not present (i.e., in winter), an eDNA signature of this species was detected in water samples. Positive detection was only made in water samples collected within $0.5 \mathrm{~m}$ of the substratum. The eDNA of $C$. sivickisi was not detected at the surface (Figure 4). Given medusae of this species are not present at the time of sampling, the eDNA signature can only be explained by the presence of polyps hidden within the coral substratum. It is likely that a shallow thermocline constrained the eDNA signature below the surface (Figure 4a).

\section{4 | DISCUSSION}

This study is the first to report on the detection of small cubozoan jellyfish in marine systems using an eDNA approach. Species-specific primers were designed for four cubozoans and eDNA analyses confirmed detection in the field against visual observations or known presence of jellyfish in proximate locations at the time of water sampling. The study is also the closest research to date to have used eDNA technologies to detect polyp stages in cubozoans. Although there was no visual detection of tiny polyps in the field, there is no other plausible explanation for the detection of eDNA when medusae are absent; eDNA, therefore, shows great potential for the location of source reefs that provide recruits to adult medusae populations. This particular finding is significant, as many cubozoans are dangerous to humans and currently there is a paucity of knowledge on the source areas for medusae and therefore how to better manage the risk of jellyfish envenomation.

Understanding the rate at which eDNA degrades in the aquatic environment can help identify if a species has been present within a certain time. Based on a simple laboratory trial, which only focused on microbial decay on eDNA, our findings indicated a fast degradation of jellyfish eDNA within the first 3 days of the animal being 


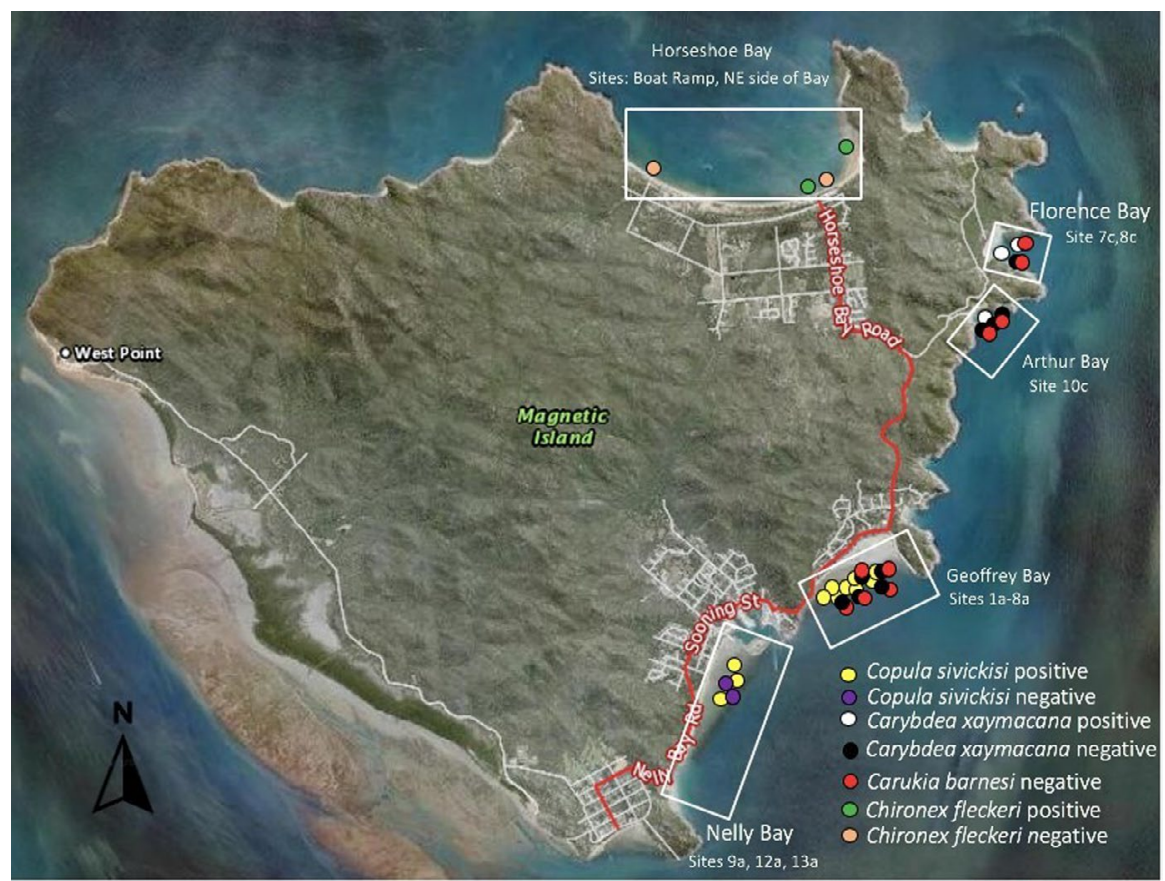

FIGURE 3 Magnetic Island, North Queensland, bays used as study sites; Nelly, Geoffrey, Arthur, Florence and Horseshoe. Dots are color coded by species where full dots represent positive and negative detections at a site for each species: Chironex fleckeri, Copula sivickisi, and Carybdea. xaymacana. Chironex were only sampled in Horseshoe Bay. Water was analyzed for Carukia barnesi in Geoffrey, Florence, and Arthur bays, with no detection being found. Visual detections were used at each of the sites in Nelly, Geoffrey, Arthur, and Florence bays
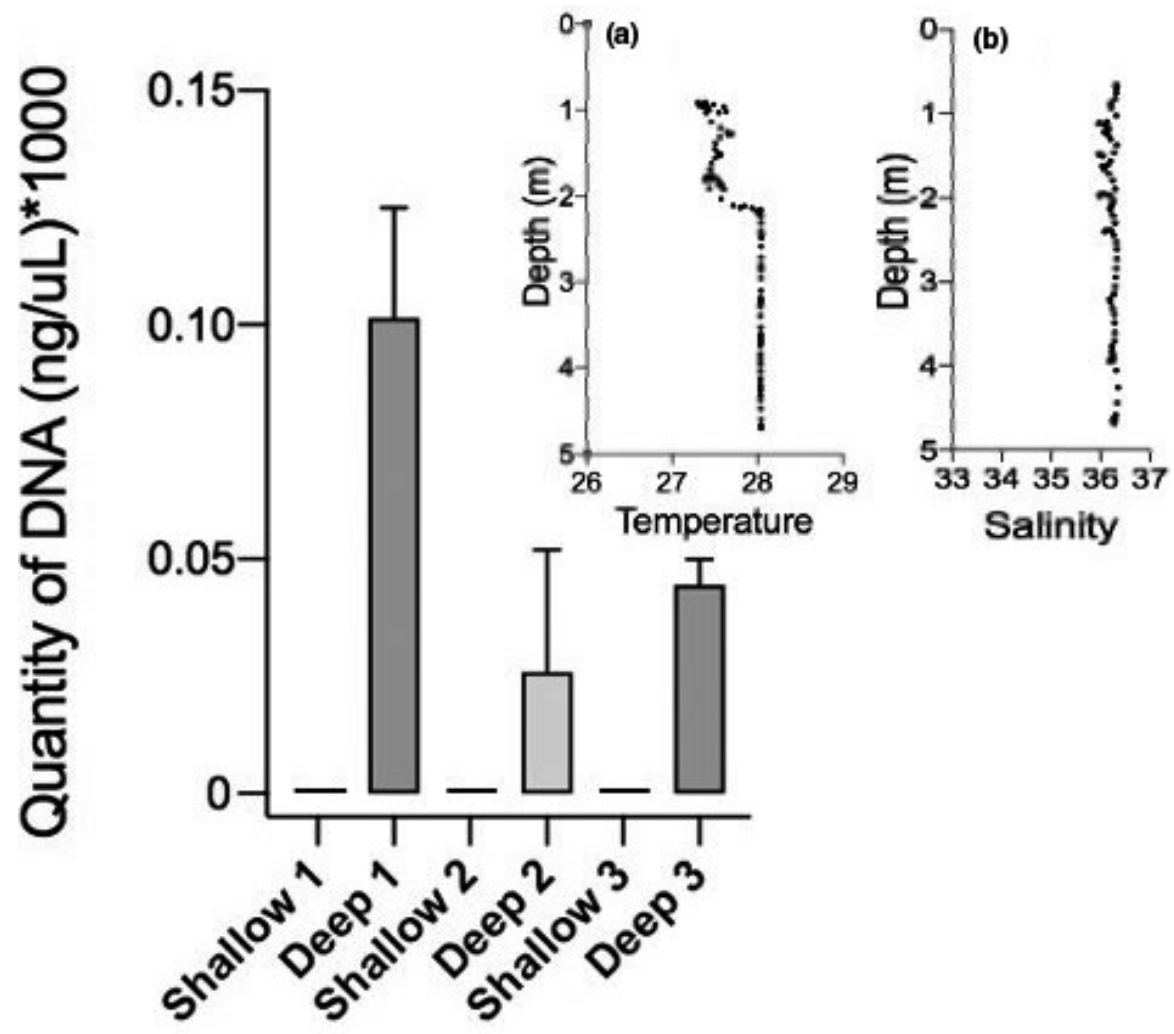

FIGURE 4 (Left) Quantity of Copula sivickisi eDNA ( $\mathrm{ng} / \mu \mathrm{l})$ when sampled from surface (Shallow) or benthic (Deep) waters surrounding Magnetic Island, along with (a) temperature and (b) salinity (PSU) profiles of the water column at the time of sampling

\section{Site}

removed from the treatment, with only a residual signature left after 9 days in some replicates. Not surprisingly, high variation was seen within the immediate removal of the organism. This has been attributed due to the clumping nature of eDNA (Furlan et al., 2016) and the variation among quantity of eDNA within each sample replicate. Our findings were similar to studies on other taxa where it is has been concluded that eDNA can remain in aquatic environments for 2 to 10 days, depending on dilution and aquatic factors (Pilliod et al., 2014; Thomsen et al., 2012). In the oceanic environment, currents, UV radiation, dilution, and microbial decay all affect 
the degradation of DNA further confirming close proximity of an organism if eDNA is detected. These findings suggest that due to the rapid decay of DNA, the target organisms we sought to detect in the field were or had been in the area recently, and/or eDNA has been carried by currents from proximate locations. Furthermore, our data are consistent with the findings from Minamoto et al. (2017), suggesting the rate of DNA degradation in jellyfish is rapid, with fastest decline in the first 3 days and that oceanic forces act on the eDNA of jellyfishes and rapidly disperse and eliminate DNA. To determine the true effect currents have on eDNA dispersal, modeling is required to determine the distance that eDNA can be advected from a source.

An environmental DNA approach was successful in the detection of cubozoan eDNA in both the laboratory and the field. For most jellyfish taxa, we knew the target species was present in the field before sampling. C. sivickisi, C. xaymacana, and C. fleckeri were detected at multiple sites where they had been visually observed. Though two sites where $C$. sivickisi medusae were visually detected (site 10a, 11a) showed no amplification, the majority of sites (84.6\%) showed positive amplification for this target species. A false negative could be attributed to inhibitors at some sites. This emphasizes the importance of taking replicate samples so that an accurate conclusion can be made on the presence of the target taxa. Another solution to inhibitors is the use of diluting samples before running a qPCR (Cao et al. 2012). Thermoclines could also be attributed to the lack of amplification at these sites as they are known to inhibit movement of materials from benthos to the surface (Gray \& Kingsford, 2003). The poor relationship between quantity of DNA and abundance of those species where we were able to obtain visual counts was probably due to the following: (a) the heterogenous distribution of DNA in the water column due to the clumping nature of eDNA (Furlan et al., 2016); (b) the source(s) of all eDNA in samples is not known, be that from organisms nearby or some distance away; (c) where samples have been taken some distance from source organisms, this leaves more time for microbial and physical decay; though this may not be the case in the current study as jellyfish were observed close to where the samples were taken; (d) the speed of dilution of eDNA from the source (Gargan et al., 2017); (e) small scale oceanography may have a role in concentration and dispersion; (f) vertical stratification of the water column preventing the eDNA from being transported through the thermocline; (g) sea water temperature, as detectability from the source may increase with temperature (Lacoursière-Roussel et al., 2016; Noble et al., 2015); (h) the volume of water being sampled and number of field replicates. The clumped nature of eDNA (Furlan et al., 2016) emphasizes the importance of replication at multiple levels, among locations, sites within location and replicates within sites.

JellyCams (JCAMS) (Schlaefer et al., 2020) and counts of jellyfish within two meters of the lights were used to determine the presence/absence of jellyfish, as well as abundance. Clearly, the JCAMs provided a more accurate estimate of relative abundance than eDNA, but the two techniques combined are useful, particularly when jellyfish are rare and are less likely to be detected in lights. For example, $C$. xaymacana was relatively rare in JCAMS imagery and visual counts, but positive detections were revealed using eDNA techniques, even without visual detection. Samples where jellyfish were known to inhabit a site provided a true positive value of detection.

The high level of detection in the field for target taxa at some sites was not surprising due to the following: (a) we had species-specific probes and primers which were optimized and cross referenced to exclude other species found in the region; (b) we could detect target taxa where they were also collected/observed; (c) no eDNA of specific taxa was detected at some "negative sites" where specific species were not expected to be found. This indicated that false-positive detections were unlikely.

An eDNA approach was shown to have utility to detect the proximate presence of $C$. sivickisi polyps. We were able to detect an eDNA signature in water samples taken close to the substratum during winter, when adult medusae were absent. Though polyps were not visually detected in situ, eDNA signatures suggested their presence at the sampled sites. At all of the sites we sampled for polyps, adult medusae were present during the previous jellyfish season (Sept-Nov). Following the mating of adults, females drop a bundle of embryos on the substratum and planulae would be released shortly after 2-3 days (Garm et al., 2015) and, therefore, would be within the restricted home range (tens of meters) of medusae (Schlaefer et al., 2020). Given a lack of evidence for false positives any eDNA of C. sivickisi that was detected could only be explained by the presence of polyps as medusae were not present for 5-6 months prior and 2 months after collection of water samples. This in turn indicates that the interpretation of results was not confounded with decomposing medusae from the benthos. Critically, the benthic polyps' DNA signature could only be detected in depth stratified sampling that including samples taken within $0.5 \mathrm{~m}$ of the substratum. It is likely the thermocline acted as a barrier reducing or preventing small amounts of DNA from the substratum reaching the surface, as thermoclines are well known for blocking the vertical passage of particles (Gray \& Kingsford, 2003) and therefore may inhibit the movement of DNA particles through the water column. The location of polyp beds in situ for most cubozoans has eluded scientists to date, due to their cryptic nature, small size, complex habitats, and low water visibility. Our study is the first to demonstrate that eDNA provides a strong predictor for the nearby location of polyps. This in turn would allow for the identification of source habitat for adult medusae. This ability to detect all life-history stages will provide new opportunities to understanding the ecology and habitat use of cubozoans.

In conclusion, in the current study, it was demonstrated that an eDNA approach is an effective technology to detect cubozoans in marine systems, both medusae and putatively the cryptic polyp life stage. With adequate replication, eDNA provides a cost-effective and less labor-intensive way to detect jellyfish that have a broad spatial and temporal variation. A major finding was that eDNA could be possibly used to detect the location of polyps that seed adult populations of cubozoans. eDNA therefore provide a new tool to potentially fast-track our understanding of jellyfish ecology. 


\section{ACKNOWLEDGMENTS}

The authors would like to thank Cecilia Villacorta Rath, Madie Cooper, and Alyssa Budd for sharing protocols throughout the project and for the valuable information provided to make the project a success. We are also grateful for the assistance in the field from volunteers.

\section{CONFLICT OF INTEREST}

None declared.

\section{AUTHORS CONTRIBUTION}

All authors conceived and planned the experiments which were undertaken in this study. Brett Bolte carried out the experiments with the assistance of Julie Goldsbury and Roger Huerlimann. Brett Bolte, Julie Goldsbury, and Michael Kingsford carried out all of the field work. Brett Bolte and Julie Goldsbury contributed to sample preparation and laboratory work with all authors having contributed to the interpretation of the results. All authors provided critical feedback and helped shape the research, analysis, and manuscript.

\section{DATA AVAILABILITY STATEMENT}

Data available on reasonable request from the authors.

\section{ORCID}

Brett Bolte iD https://orcid.org/0000-0002-5395-1550

Dean Jerry iD https://orcid.org/0000-0003-3735-1798

Michael Kingsford (iD https://orcid.org/0000-0003-1704-6198

\section{REFERENCES}

Bayha, K. M., Dawson, M. N., Collins, A. G., Barbeitos, M. S., \& Steven, H. D. H. (2010). Evolutionary relationships among scyphozoan jellyfish families based on complete taxon Sampling and phylogenetic analyses of $18 \mathrm{~S}$ and $28 \mathrm{~S}$ ribosomal DNA. Integrative and Comparative Biology, 50(3), 436-455.

Bentlage, B., Cartwright, P., Yanagihara, A. A., Lewis, C., Richards, G. S., \& Collins, A. G. (2010). Evolution of box jellyfish (Cnidaria: Cubozoa), a group of highly toxic invertebrates. Proceedings of the Royal Society B: Biological Sciences, 277(1680), 493-501.

Cao, Y., Griffith, F., Dorevitch, S., \& Weisberg, S. B. (2012). Effectiveness of qPCR permutations, internal controls and dilution as means for minimizing the impact of inhibition while measuring Enterococcus in environmental waters. Journal of Applied Microbiology, 113(1), 66-75.

Ender, A., \& Schierwater, B. (2003). Placozoa are not derived cnidarians: Evidence from molecular morphology. Molecular Biology and Evolution, 20(1), 130-134. https://doi.org/10.1093/molbev/msg018

Furlan, E. M., Gleeson, D., Hardy, C. M., \& Duncan, R. P. (2016). A framework for estimating the sensitivity of edna surveys. Molecular Ecology Resources, 16(3), 641-654. https://doi.org/10.1111/17550998.12483

García-Rodríguez, J., Lewis Ames, C., Marian, J. E. A. R., \& Marques, A. C. (2018). Gonadal histology of box jellyfish (Cnidaria: Cubozoa) reveals variation between internal fertilizing species Alatina alata (Alatinidae) and Copula sivickisi (Tripedaliidae). Journal of Morphology, 279(6), 841-856. https://doi.org/10.1002/jmor.20815

Gargan, L. M., Morato, T., Pham, C. K., Finarelli, J. A., Carlsson, J. E. L., \& Carlsson, J. (2017). Development of a sensitive detection method to survey pelagic biodiversity using eDNA and quantitative PCR: A case study of devil ray at seamounts. Marine Biology, 164(5), 1. https://doi. org/10.1007/s00227-017-3141-x
Garm, A., Lebouvier, M., \& Tolunay, D. (2015). Mating in the box jellyfish Copula sivickisi-Novel function of cnidocytes. Journal of Morphology, 276(9), 1055-1064. https://doi.org/10.1002/jmor.20395

Gaynor, J. J., Bologna, P. A. X., Restaino, D. J., \& Barry, C. L. (2017). qPCR detection of early life history stage chrysaora quinquecirrha (sea nettles) in Barnegat Bay, New Jersey. Journal of Coastal Research, 78(78), 184-192. https://doi.org/10.2112/SI78-014.1

Gray, C. A., \& Kingsford, M. J. (2003). Variability in thermocline depth and strength, and relationships with vertical distributions of fish larvae and mesozooplankton in dynamic coastal waters. Marine Ecology Progress Series, 247, 211-224. https://doi.org/10.3354/meps247211

Hartwick, R. F. (1991). Distributional ecology and behaviour of the early life stages of the box-jellyfish Chironex fleckeri. Hydrobiologia, 216217(1), 181-188. https://doi.org/10.1007/BF00026460

Jerde, C. L., Mahon, A. R., Chadderton, W. L., \& Lodge, D. M. (2011). "Sight-unseen" detection of rare aquatic species using environmental DNA: eDNA surveillance of rare aquatic species. Conservation Letters, 4(2), 150-157. https://doi.org/10.1111/j.1755-263X.2010.00158.x

Keskin, E., Unal, E. M., \& Atar, H. H. (2016). Detection of rare and invasive freshwater fish species using eDNA pyrosequencing: Lake Iznik ichthyofauna revised. Biochemical Systematics and Ecology, 67, 29-36. https://doi.org/10.1016/j.bse.2016.05.020

Kingsford, M. J., Becken, S., Bordehore, C., Fuentes, V. L., Pitt, K. A., \& Yangihara, A. A. (2018). Empowering Stakeholders to Manage Stinging Jellyfish: A Perspective. Coastal Management, 46(1), 1-18. https://doi.org/10.1080/08920753.2018.1405326

Kingsford, M. J., \& Mooney, C. J. (2014). The ecology of box jellyfishes (Cubozoa). In K. A. Pitt, \& C. H. Lucas (Eds.), Jellyfish blooms (pp. 267302). Springer.

Kingsford, M. J., Seymour, J. E., \& O'Callaghan, M. D. (2012). Abundance patterns of cubozoans on and near the Great Barrier Reef. Hydrobiologia, 690(1), 257-268. https://doi.org/10.1007/s1075 0-012-1041-0

Lacoursière-Roussel, A., Rosabal, M., \& Bernatchez, L. (2016). Estimating fish abundance and biomass from eDNA concentrations: Variability among capture methods and environmental conditions. Molecular Ecology Resources, 16(6), 1401-1414. https://doi. org/10.1111/1755-0998.12522

Minamoto, T., Fukuda, M., Katsuhara, K. R., Fujiwara, A., Hidaka, S., Yamamoto, S., Takahashi, K., \& Masuda, R. (2017). Environmental DNA reflects spatial and temporal jellyfish distribution. PLoS One, 12(2), 15. https://doi.org/10.1371/journal.pone.0173073

Noble, T., Robson, H., Saunders, R., \& Jerry, D. (2015). The utility of eDNA as a tilapia surveillance tool. Report. Invasive Animalc Cooperative Research Centre, Canberra, ACT, Australia.

Pilliod, D. S., Goldberg, C. S., Arkle, R. S., \& Waits, L. P. (2014). Factors influencing detection of eDNA from a stream-dwelling amphibian. Molecular Ecology Resources, 14(1), 109-116. https://doi. org/10.1111/1755-0998.12159

Ponce, D., Brinkman, D. L., Luna-Ramírez, K., Wright, C. E., \& DorantesAranda, J. J. (2015). Comparative study of the toxic effects of Chrysaora quinquecirrha (Cnidaria: Scyphozoa) and Chironex fleckeri (Cnidaria: Cubozoa) venoms using cell-based assays. Toxicon, 106, 57-67. https://doi.org/10.1016/j.toxicon.2015.09.014

Renshaw, M. A., Olds, B. P., Jerde, C. L., McVeigh, M. M., \& Lodge, D. M. (2015). The room temperature preservation of filtered environmental DNA samples and assimilation into a phenol-chloroform-isoamyl alcohol DNA extraction. Molecular Ecology Resources, 15(1), 168-176. https://doi.org/10.1111/1755-0998.12281

Robson, H. L. A., Noble, T. H., Saunders, R. J., Robson, S. K. A., Burrows, D. W., \& Jerry, D. R. (2016). Fine-tuning for the tropics: Application of eDNA technology for invasive fish detection in tropical freshwater ecosystems. Molecular Ecology Resources, 16(4), 922-932. https://doi. org/10.1111/1755-0998.12505

Schlaefer, J. A., Wolanski, E., Yadav, S., \& Kingsford, M. J. (2020). Behavioural maintenance of highly localised jellyfish (Copula 
sivickisi, class Cubozoa) populations. Marine Biology, 167(4), https:// doi.org/10.1007/s00227-020-3646-6

Seymour, J. (2002). One touch of venom. Natural History, 111, 72-75.

Simpfendorfer, C. A., Kyne, P. M., Noble, T. H., Goldsbury, J., Basiita, R. K., Lindsay, R., Shields, A., Perry, C., \& Jerry, D. R. (2016). Environmental dna detects critically endangered largetooth sawfish in the wild. Endangered Species Research, 30, 109-116. https://doi.org/10.3354/ esr00731

Thomsen, P. F., Kielgast, J., Iversen, L. L., Møller, P. R., Rasmussen, M., \& Willerslev, E. (2012). Detection of a diverse marine fish fauna using environmental DNA from seawater samples. PLoS One, 7(8), e41732. https://doi.org/10.1371/journal.pone.0041732

Tibballs, J., Tibballs, H. A., Li, R., Gershwin, L.-A., \& Winkel, K. D. (2012). Australian carybdeid jellyfish causing "Irukandji syndrome". Toxicon, 59(6), 617-625. https://doi.org/10.1016/j.toxic on.2012.01.006

Uthicke, S., Lamare, M., \& Doyle, J. R. (2018). eDNA detection of corallivorous seastar (Acanthaster cf. Solaris) outbreaks on the great barrier reef using digital droplet PCR. Coral Reefs, 37(4), 1229-1239. https:// doi.org/10.1007/s00338-018-1734-6

van Walraven, L., Driessen, F., van Bleijswijk, J., Bol, A., Luttikhuizen, P. C., Coolen, J. W. P., Bos, O. G., Gittenberger, A., Schrieken, N., Langenberg, V. T., \& van der Veer, H. W. (2016). Where are the polyps? Molecular identification, distribution and population differentiation of Aurelia aurita jellyfish polyps in the southern North Sea area. Marine Biology, 163, 172-172. https://doi.org/10.1007/s0022 7-016-2945-4

Villacorta-Rath, C., Adekunle, A. I., Edmunds, R. C., Strugnell, J. M., Schwarzkopf, L., \& Burrows, D. (2020). Can environmental DNA be used to detect first arrivals of the cane toad, Rhinella marina, into novel locations? Environmental DNA, 2(4), 635-646. https://doi. org/10.1002/edn3.114

Walther, B. D., Kingsford, M. J., \& McCulloch, M. T. (2013). Environmental Records from Great Barrier Reef Corals: Inshore versus Offshore Drivers. PLoS One, 8(10), e77091. https://doi.org/10.1371/journ al.pone.0077091

Williams, K. E., Huyvaert, K. P., \& Piaggio, A. J. (2016). No filters, no fridges: A method for preservation of water samples for eDNA analysis. BMC Research Notes, 9(1), 298. https://doi.org/10.1186/s1310 4-016-2104-5

\section{SUPPORTING INFORMATION}

Additional supporting information may be found online in the Supporting Information section.

How to cite this article: Bolte B, Goldsbury J, Jerry D, Kingsford M, Huerlimann R. Validation of eDNA as a viable method of detection for dangerous cubozoan jellyfish.

Environmental DNA. 2021;3:769-779. https://doi.org/10.1002/ edn3.181 